\title{
IMPOSTURAS INTELECTUAIS
}

\section{A sociologia (auto)crítica de Pierre Bourdieu}

ESBOÇO DE AUTO-ANÁLISE

de Pierre Bourdieu. São Paulo: Companhia das Letras, 2005.

ENIO PASSIANI

"Isto não é uma biografia." Essa a epígrafe - e também uma espécie de advertência ao leitor - que serve de abertura ao mais recente livro de Pierre Bourdieu publicado no Brasil. E, se não é gênero biográfico, como o título da obra poderia indicar, então o que é?

Avesso a esse tipo de literatura por considerá-la convencional e ilusória, Bourdieu atesta que "compreender é primeiro compreender o campo com o qual e contra o qual cada um se faz" (p.40), o que significa dizer, portanto, que o autor se empenhou em escrever sua própria história social.Ou seja,com baseem sua trajetória, experiências, expectativas, desilusões e a "emoção raciocinada" - como afirma Sergio Miceli na introdução -, Bourdieu reconstrói, mobilizando um tremendo esforço de reflexividade, o processo de estruturação do campo acadêmico francês em curso desde os anos 1950, data que marca seu ingresso no mundo intelectual como aluno da Escola Normal Superior no curso de filosofia. Em tal processo, ao tomar-se como objeto de análise, Bourdieu não apenas escreve a história de si mesmo, como se preocupa em contar uma parte da história da constituição e afirmação da sociologia na França.

No momento em que ele entra na universidade, a filosofia se apresentava como disciplina no ápice da hierarquia escolar, ao passo que a sociologia aparecia como "disciplina pária" (p. 67), ocupando posição subalterna. É em torno do curso de filosofia que se forma certa "aristocracia escolar" que determinava as ambições intelectuais tanto daqueles queensaiavam os primeiros passos no seio do curso, como daqueles que já dispunham do diploma escolar, marca distintiva em relação aos iniciantes e colegas que se formavam noutras disciplinas. Criava-se, assim, entre os filósofos (ou postulantes a tal) um sentimento social de pertencer a uma "essência superior", como diz Bourdieu; um "espírito de corpo" (p.43) alimentado pelas disposições e tomadas de posição que ajudava a criar e que provocavam conseqüências inclusive na produção acadêmica, impedindo os filósofos, por exemplo, de ligar-se a certas disciplinas, teorias e objetos considerados menos "nobres" ou "dignos", os 
quais, por sua vez, os afastavam do mundo social ${ }^{1}$. Configurava-se o que Bourdieu chamou alhures de "efeito de campo" 2 : a sensação de pertencimento, as afinidades intelectuais e até pessoais, a adesão às regras formuladas pelos agentes e agências daquele campo específico, a formação de um certo habitus que orientava, em boa medida, as escolhas e os posicionamentos de tais agentes. E era esse "efeito" que produzia a ilusão da autonomia absoluta da produção do discurso filosófico, distanciando-o do "mundo real" (p.44), dos problemas concretos que necessitavam ser estudados e compreendidos.

Bourdieu confessa que já durante o curso demonstrara disposição em afastar-se da filosofia e repudiar suas "grandezas enganosas" (p.71)3. Daí a oposição, nunca desprovida de respeito, a Raymond Aron e Sartre, figura hegemônica do campo cultural francês naquele período e símbolo do intelectual ideal, cuja atuação - que se alargava para além da filosofia, como o teatro e a literatura - contribuiu sobremaneira para reforçar o mito do pensador autônomo, livre de qualquer constrangimento social. Bourdieu, nesse episódio, chama a atenção para o jogo relacional que se estabelece entre o agente e a instituição da qual faz parte:

Produtos puros de uma instituição escolar triunfante, que concedia a sua "elite" um reconhecimento incondicional, transformando, por exemplo, um concurso escolar de recrutamento (a agregação em filosofia) numa instância de consagração intelectual [...], essas espécies de crianças-prodígios se viam conferir por decreto, aos vinte anos de idade, os privilégios e as obrigações do gênio. Numa França econômica e politicamente diminuída, mas sempre tão senhora de si intelectualmente, podiam se consagrar com toda a inocência à missão que lhes atribuíam a Universidade e toda uma tradição universitária habitada pela certeza de sua universalidade: ou melhor, uma espécie de magistério universal da inteligência 4.

Participar do campo significa incorporar um habitus socialmente construído, compartilhar da illusio que atrai e congrega determinados indivíduos e os afasta de tantos outros, numa disputa legítima por prestígio, reconhecimento, poder e hegemonia. A instituição escolar, internalizada pelos agentes e por meio da performance destes últimos, produzia a ilusão de liberdade - fortalecida pela consagração e privilégios concedidos àqueles que cumpriam rigorosamente com as obrigações do sistema escolar e recebiam, em troca, os signos de mérito e "talento" oficialmente reconhecidos. Essa ilusão ocultava, de um lado, os interesses dos participantes numa disputa constante por bens simbólicos e, de outro, a distribuição desigual dos bens culturais entre os estudantes de diferentes classes sociais.

A filosofia, como disciplina dominante, precisava reproduzir a hegemonia, assim como os filósofos, de maneira homóloga, a condição de intelectuais (supostamente) superiores. Garantir essa posição implicava deslegitimar as disciplinas concorrentes e seus especialistas,
[1] Segundo Bourdieu, a reaproximação com o cenário social não acontecia pela via do conhecimento, mas pelo engajamento político, principalmente pela adesão aos partidos considerados de esquerda no espectro ideológico.

[2] Ver, entre outros, Bourdieu, Pierre. A ontologia politica de Martin Heidegger. Campinas: Papirus, 1989.

[3] O incômodo de Bourdieu diante do discurso filosófico já aparecia nos interesses manifestados, durante os tempos de estudante, pela história e filosofia da ciência, assim como a atração pela fenomenologia de Husserl e depois pela sociologia fenomenológica de Schütz - ramos do conhecimento que, em certo sentido, faziam-no sentir-se mais próximo da realidade histórica.

[4] Bourdieu, Pierre. Esboço de autoanálise. São Paulo: Companhia das Letras, 2005, p. 57. 
[5] Consultar Bourdieu, Pierre. "A escola conservadora: as desigualdades frente à escola e à cultura". Escritos de educação. Petrópolis: Vozes, 1999.

[6] Justifica-se, assim, o uso da palavra talento, logo acima, entre aspas, pois sob essa rubrica pode se esconder uma dessas estratégias de naturalização, e por conseguinte ocultamento, de diferenças socialmente criadas que agem sobre o desempenho escolar e influenciam tanto no êxito como no fracasso dos alunos, em geral encarados como o resultado mais puro da ação individual.

[7] Said, Edward W. "Exílio intelectual:expatriados e marginais". Representações do intelectual. São Paulo: Companhia das Letras, 2005 , p. 57.

[8] Idem, p. 68.

[9] Interessante notar que Bourdieu traz à tona como possível fator explicativo um tema atualmente tão fora de moda: a posição que o indivíduo ocupa na estrutura de classes. tornando universais os mitos e a ideologia criados no campo filosófico. Exemplo disso é a crença na "vulgaridade científica" (p.49) da sociologia. Como contraponto à perspectiva sociológica, encarada como positivismo rasteiro, os filósofos defendiam a individualidade criativa do autor, espécie de atualização da concepção romântica do gênio, produto, e ao mesmo tempo produtora, da "ideologia do dom"5, mecanismo de naturalização das desigualdades sociais e de sua reprodução no domínio da cultura ${ }^{6}$. Destarte, na origem de certa arrogância na postura e mesmo no empreendimento intelectual, encontrava-se "ingenuidade" e até "inocência" de "grandes adolescentes burgueses para quem tudo deu certo" (p. 57). Mas a cegueira, a incapacidade de esses pensadores pensarem o próprio mundo do pensamento do qual participavam e ajudavam a construir, incomodava Bourdieu, e bastante. Por isso sua aproximação de Georges Canguilhem, que, como ele, apesar da importância e posição de destaque, vinha também de origem humilde, e talvez por essa razão oferecia alguma resistência aos modelos - teóricos e de conduta - convencionais do campo e se comportava como se não pertencesse por completo àquele ambiente.

Nota-se neste livro de Bourdieu, e arrisco afirmar que em toda a sua obra, a necessidade de o intelectual arrogar para si, se quiser de fato realizar um trabalho crítico, a condição de exilado. Pois assim "vive num estado intermediário, nem de todo integrado ao novo lugar, nem totalmente liberto do antigo"7, constantemente insatisfeito e incomodado porque se encontra a uma distância suficiente para "ver as coisas não apenas como elas são, mas como se tornaram o que são"8. É o exílio em sua própria terra que permitea Bourdieu interrogaro mundo intelectual, escrutinar as engrenagens do poder, as contendas, as alianças, as estratégias de atuação que não poderiam deixar de afetar a produção dos bens culturais; enfim, desencantá-lo para melhor entendê-lo.

No caso do sociólogo francês, como ele mesmo sugere, parte dessa condição deriva da origem de classe, geradora de disposições originais que acabaram por orientar certas escolhas e condutas 9 . Nascido no seio de uma comunidade rural na região do Béarn, filho de um funcionário dos correios, Bourdieu vivenciou experiências decisivas nos internatos pelos quais passou durante a adolescência. Neles experimentou o contato mais próximo com os círculos burgueses e descobriu as diferenças sociais; talvez pela primeira vez, e apesar do sucesso como estudante, sentiu-se deslocado, não integrado àquele universo. A oposição entre a consagração escolar, que vinha conquistando de forma gradativa, e a baixa extração social, da qual tinha consciência, resultava num "habitus clivado, movido por tensões e contradições" (p. 123), que explicaria em algum grau a relação ambivalente de Bourdieu com a instituição escolar: mescla de rebelião e submissão, ruptura e esperança, apego e dissidência às regras do jogo acadêmico e científico.

O espírito combativo de Pierre Bourdieu foi moldado aos poucos, num processo que envolveu um conjunto de fatores: a origem social, a 
herança cultural recebida da família, as influências do pai — trabalhador sindicalizado, republicano, eleitor da esquerda e que desde cedo ensinara ao filho o respeito pelos mais humildes - a experiência no internato, as preferências intelectuais e pessoais desenvolvidas ainda no curso de filosofia e, parte importante de sua trajetória, a permanência na Argélia, país que vivia as agruras e os dramas de uma guerra de libertação por um período de três anos. Lá se concretiza a passagem, havia algum tempo desejada, da filosofia para as ciências sociais, especificamente a etnologia, e tem início sua prática docente na Faculdade de Letras de Argel.

Quando volta a Paris, Bourdieu promove uma segunda guinada na profissão: a migração da etnologia para a sociologia ${ }^{10}$. Embora o autor reconheça o débito em seus primeiros trabalhos etnológicos sobre o parentesco, o ritual e a economia pré-capitalista realizados junto à população cabila argelina com o estruturalismo lévi-straussiano - assim como reconhece a importância do estruturalismo para a legitimação de uma ciência social, a antropologia, como disciplina não apenas respeitável mas dominante ${ }^{11}$ - a ruptura não tarda a acontecer. E a principal causa foi de natureza teórico-metodológica, já que suas análises pretendiam reintroduzir a prática do agente por meio da observação de suas interações intersubjetivas, da capacidade de invenção e improvisação diante das estruturas sociais, tornando possível realizar certos questionamentos impensáveis para a antropologia, mas que a sociologia poderia realizar ${ }^{12}$.

Aquele espírito combativo serviu de princípio norteador para um projeto intelectual original e ousado, que Bourdieu começava a desenvolver a partir do começo dos anos 1960 no campo da sociologia. Ao longo da carreira e obra, esse parvenu insubmisso procurou estender ao máximo os limites da razão sociológica e testar o seu poder explicativo. Desenvolveu, desse modo, uma ciência social que desde cedo se mostrou rebelde, insolente até, caracterizada por uma alta voltagem crítica visível no tratamento que dedicou a um de seus principais objetos de investigação: o trabalho intelectual, seja literário, artístico, pedagógico ou científico. Empreendeu, logo, uma reflexão sobre si mesmo, sobre seu próprio trabalho, num exercício de auto-análise que implicava descoberta e reencontro consigo, mas também desfraldava, de forma corajosa e ácida, os mecanismos sociais que fazem funcionar o campo da produção do conhecimento. Nesse sentido, a sociologia promove o desencantamento, "quebra o charme"13 de uma atividade que parece dotada de sacralidade e em torno da qual se molda uma atitude respeitosa em excesso. Justamente por tal motivo a sociologia proporciona autonomia aos praticantes. Autonomia que, a um só tempo, requer e autoriza algumas imposturas intelectuais e serve de motor à ação dos agentes.

Como todo grande autor, Bourdieu ensina muito, e entre as várias lições desse pequeno-grande livro está o incentivo a suspeitar de nossas interpretações e das alheias. Então, a maior homenagem que poderíamos lhe prestar não seria exatamente desconfiar do esboço de autocompreensão que ele oferece? Quando perguntado, em entrevista concedida a J.
[10] Ao final do livro há uma apresentação esquemática e útil da vida e da obra de Pierre Bourdieu, organizada por Sergio Miceli, na qual o leitor poderá acompanhar atentamente os detalhes de tal percurso.

[11] Ver Bourdieu, Pierre. Coisas ditas. São Paulo: Brasiliense, 2004, p.18.

[12] Idem, pp. 21-22.

[13] Pierre Bourdieu. Lições de aula. São Paulo: Ática, 1994, p. 61. 
[14] Consultar Bourdieu, Pierre. Coisas ditas. São Paulo: Ática, 2004, pp. $65-68$.

[15] Idem, p. 67.
Heilbron e B. Maso ${ }^{14}$, sobre sua relação com a tradição marxista, Bourdieu afirmou que era possível e mais interessante em termos científicos "pensar com um pensador contra esse pensador" 15 , ou seja, a partir de Weber contra Weber, com Marx e Weber contra Durkheim, e assim por diante, porque é desse modo, diz ele, que a ciência avança, superando o conhecimento acumulado pelos antecessores, atualizando-o. Não me parece absurdo, tampouco desrespeitoso, usar Bourdieu contra Bourdieu.

O livro, acredito, não deixará de seduzir o leitor, mas suscitará, igualmente, algumas dúvidas. No texto, mistura de biografia, obra e reflexão crítica, não contamos com outra fonte de informação senão as memórias do próprio autor. Não há como averiguar a veracidade do relato. Para isso, seria preciso cruzar os "dados" fornecidos com outras fontes (biografia e autobiografias dos interlocutores citados, a leitura das obras com as quais o sociólogo dialogava), reconstruir a história do campo intelectual no período com base em bibliografia mais extensa, consultar documentos, realizar entrevistas com os aliados e seus adversários, noutros termos, utilizar um aparato de coleta de dados com o zelo metodológico aconselhado pelo mesmo Bourdieu. Caso contrário, podemos supor (e temer) que a história social do autor e a história do campo acadêmico-científico oferecidas obedecem apenas às disposições mnemônicas de Bourdieu, que variam de acordo com a posição ocupada no referido campo. Se ocupava, sem sombra de dúvida, um posto hegemônico no ambiente universitário francês, então seu Esboço de auto-análise não contribuiria para a reprodução de seu poder no interior do campo? O livro não seria, pois, além de esforço de auto-reflexão, um exercício de autoconsagração, por mais que o autor sustente que as intenções não são deliberadas, nem estratégias intencionais de preservar-lhe o capital simbólico? (p.96) Quiçá não sejam mesmo, até porque o autor já havia acumulado bens simbólicos o bastante para não ser ameaçado por nenhum outro concorrente. O que não elimina a hipótese - cujo teste não cabe nos limites desta resenha - de que, consciente de que a dinâmica do campo é definida pelas lutas e disputas internas, Bourdieu estivesse, mesmo inconscientemente - devido ao habitus incorporado ao longo da vida intelectual -, preocupado em assegurar sua posteridade, cavando um lugar sólido na história da sociologia, não apenas a francesa. Aliás, se essa hipótese fizer sentido, podemos supor que a estratégia empregada, absolutamente legítima, para buscar e ocupar um lugar ao sol no meio acadêmico, revela-se sobretudo nos momentos em que o autor avalia, por meio de pesquisas rigorosas, o funcionamento das esferas responsáveis pela produção (e reprodução) do saber. É em nome da objetividade científica, tão valorizada por Bourdieu, que conjecturamos se não há sobrecarga de subjetividade no ensaio - expressa inclusive formalmente pelo uso abusivo dos parênteses - a ponto de arranhar a credibilidade de algumas passagens narradas pelo autor.

Adespeito das questões que o livro de Bourdieu é incapaz de responder, mas capaz, sim, de inspirar, estamos diante de uma verdadeira aula 
na qual aprendemos que a sociologia não é e nem pode ser uma disciplina que se presta à canonização de autores e obras, mesmo daqueles que admiramos. Se quisermos nos tornar mais do que meros lectores e auctores autênticos, devemos fundar nossa própria tradição de pensamento sem descartar certa "angústia da influência". At last but not least, o debate das idéias deve ser severamente crítico, mas sem abandonaro respeito e a generosidade para com os interlocutores. Essas são lições que devemos tentar seguir, mesmo com a suspeita de que nem o próprio mestre que as ensina foi capaz de levá-las integralmente a cabo.

ENIO PASSIANI é mestre e doutorando em Sociologia pela USP. 